\title{
A detailed density profile of the Dome Fuji (Antarctica) shallow ice core by X-ray transmission method
}

\author{
A. Hori,${ }^{1}$ K. Tayuki,${ }^{1}$ H. Narita,${ }^{1}$ T. Hondoh,${ }^{1}$ S. Fujita, ${ }^{2}$ T. Kameda,${ }^{3}$ H. Shoji,${ }^{3}$ N. Azuma,${ }^{4}$ \\ K. Kamiyama, ${ }^{5}$ Y. Fujin ${ }^{5}$ H. Motoyama, ${ }^{5}$ O. Watanabe ${ }^{5}$ \\ ${ }^{1}$ Institute of Low Temperature Science, Hokkaido University, Sapporo, Hokkaido 060-0819, Japan \\ ${ }^{2}$ Department of Applied Physics, Hokkaido University, Sapporo, Hokkaido 060-8626, Japan \\ ${ }^{3}$ Kitami Institute of Technology, Koen-cho 165, Kitami, Hokkaido 090-8507, Japan \\ ${ }^{4}$ Department of Mechanical Engineering, Nagaoka University of Technology, Nagaoka, Niigata 940-2188, Japan \\ ${ }^{5}$ National Institute of Polar Research, Kaga 1-9-10, Itabashi-ku, Tokyo 173-8515, Japan
}

\begin{abstract}
An X-ray transmission method has been developed to obtain a continuous profile of bulk densities of ice cores. Intensities of X-rays transmitted through an icecore sample were continuously measured by an X-ray detector during translation of the sample across the X-ray beam. A thick section of an ice core with a constant thickness was prepared by band-sawing followed by microtome planing. The X-ray intensity profile obtained was converted to a density profile using a calibration curve for X-ray absorption vs ice thickness. Using this method, spatial resolution of the density profile was down to $1 \mathrm{~mm}$. X-ray radiographs were also taken on a two-dimensional detector imaging plate, in order to observe layer structures of the ice cores.

The method was applied to Dome Fuji (Antarctica) ice cores from the surface to $110 \mathrm{~m}$ depth. From the density profile obtained, we calculated the power spectrum of the density variation by the discrete Fourier transform, and obtained several peaks at different frequencies. The center period in the spectrum was close to the annual accumulation thickness at the drill site.
\end{abstract}

\section{INTRODUCTION}

A density profile of ice cores is one of the fundamental datasets in ice-core analysis. The densification process of polar ice cores has been intensely studied (Herron and Langway, 1980; Wilkinson, 1988; Langway and others, 1993). However, the bulk density of ice cores has generally been measured by the conventional volumetric method, whose resolution for the depth is at best several tens of $\mathrm{mm}$. A detailed density profile will provide new and useful information to improve understanding of the densification process. Since the density of ice cores is closely related to the permeability (Langway and others, 1993), density-profile data are necessary to estimate the age difference between polar ice and the air trapped in the bubbles (Schwander and Stauffer, 1984; Schwander and others, 1997).

Non-destructive high-resolution density measurements using gamma-ray attenuation have been carried out, and the correlation between the density and the electrical-conductivity measurement (ECM) profile is reported by Gerland and others (1999). The timing of the density and the ECM suggests that the density variations in the ice cores reflect seasonal variations. Seasonal variations of the density have also been found for about 15 samples measured at intervals of about $10 \mathrm{~m}$ depth (Tayuki and others, 1997).

In the present paper, a detailed density profile of the Dome Fuji (Antarctica) shallow ice cores measured on more than 50 samples, corresponding to $25 \mathrm{~m}$ depth, is shown and analyzed by the discrete Fourier transform (DFT). The samples were chosen so that the depths could be almost con-

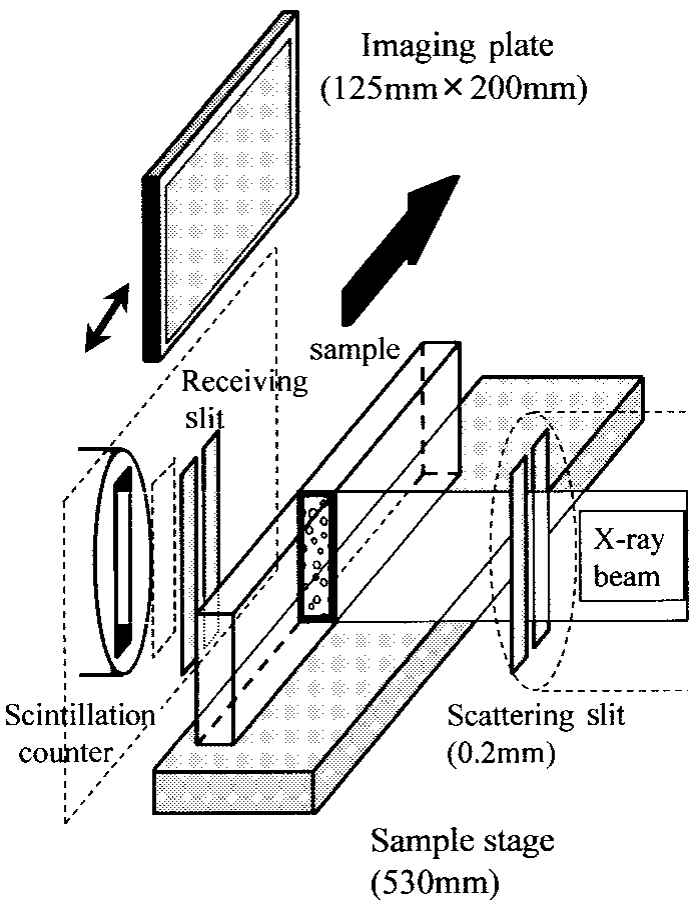

Fig. 1. Schematic diagram of the X-ray transmission measurement system around the sample. The X-ray beam is transmitted through the sample, while the sample on the stage moves in the direction shown by an arrow. The transmitted $X$-ray intensity is counted every $1 \mathrm{~mm}$ using a scintillation counter, which provides a detailed density profile. Using an IP, a two-dimensional X-ray image can be obtained. 


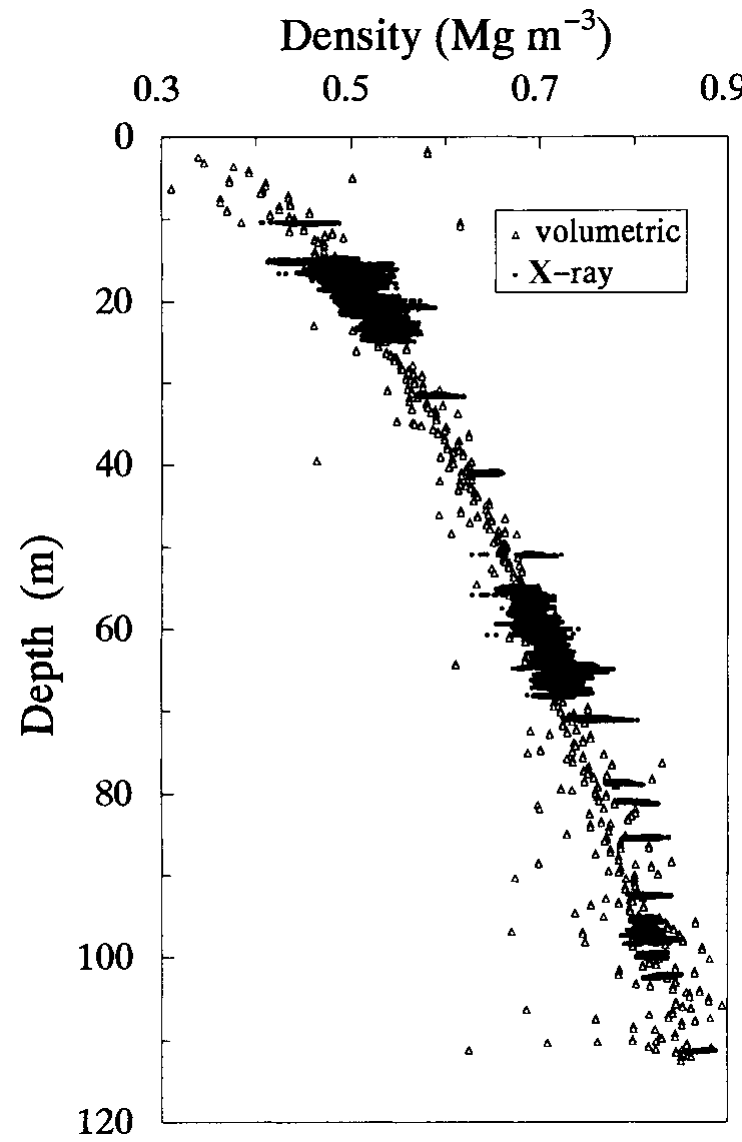

Fig. 2. The density profile of the Dome Fuji shallow ice core measured by the X-ray transmission method (dots) and by the conventional volumetric method (open triangles). The latter measurement was made at the drilling site.

tinuous between the intervals 15-25, 55-65 and 95-100 m. Xray radiographs taken on an imaging plate (IP) show the two-dimensional structure of the ice cores. The power spectra of the density variations were calculated for each sample.

\section{EXPERIMENTAL PROCEDURE}

Thick sections of ice-core samples were prepared by bandsawing followed by microtome planing. The roughness of the surface of each sample was considered to be much less than $1 \%$ of the sample thickness. The samples were typically about $500 \mathrm{~mm}$ long, $30 \mathrm{~mm}$ thick and $40 \mathrm{~mm}$ high.

Figure 1 shows a schematic diagram of the X-ray transmission measurement system which is operated in a cold room at $-20^{\circ} \mathrm{C}$. In order to obtain highly sensitive density variations, the $\mathrm{X}$-ray generator was operated at low voltage $(30 \mathrm{kV})$. The width of the optical slit was limited to $0.05 \mathrm{~mm}$ for the divergence slit, $0.2 \mathrm{~mm}$ for the scattering slit and $0.2 \mathrm{~mm}$ for the receiving slit, as shown in Figure 1, to obtain high-resolution data for the depth. Under these optical-slit conditions, the intensities of transmitted X-rays were measured every $1 \mathrm{~mm}$. Accordingly, the spatial resolution of this method is $1 \mathrm{~mm}$ for the present measurements. The profile of transmitted X-ray intensities was converted to that of densities, using a calibration curve of transmitted intensities as a function of thickness of pure bulk ice. A transmitted X-ray intensity, $I$, is described as

$$
I=I_{0} \exp \left(-\mu_{\text {ice }} t_{\text {eff }}\right)
$$

where $I_{0}, \mu_{\text {ice }}$ and $t_{\text {eff }}$ are an incident X-ray intensity, the linear absorption coefficient of ice and the effective thickness of the sample, respectively. The density $\rho$ is calculated according to the equation:

$$
\rho=0.917 \frac{t_{\text {eff }}}{t_{\mathrm{s}}},
$$

where $t_{\mathrm{s}}$ is the thickness of the sample. Considering the statistical error of X-ray intensity measurement and fluctuations of the sample thickness along the sample axis, the error included in each data point of the density profile is estimated at about $1 \%$.

$\mathrm{X}$-ray radiographs were taken on IPs. The length of an IP is about $20 \mathrm{~cm}$, while that of the longest sample is about $50 \mathrm{~cm}$. Thus the data were compressed into one-third of the length of the sample axis. The spatial resolution of IPs was originally $100 \mu \mathrm{m}$ by $100 \mu \mathrm{m}$. Accordingly, the spatial resolution of the data along the sample axis was considered to be about $300 \mu \mathrm{m}$ in this measurement.

\section{RESULTS AND DISGUSSION}

\section{Density profile}

A detailed density profile of ice cores was calculated using Equations (1) and (2). Figure 2 shows the density profile obtained in the present work and that measured by the conventional volumetric method (Watanabe and others, 1997a). The average density of each sample was consistent with the density measured in the above-mentioned way. In Figure 2, the

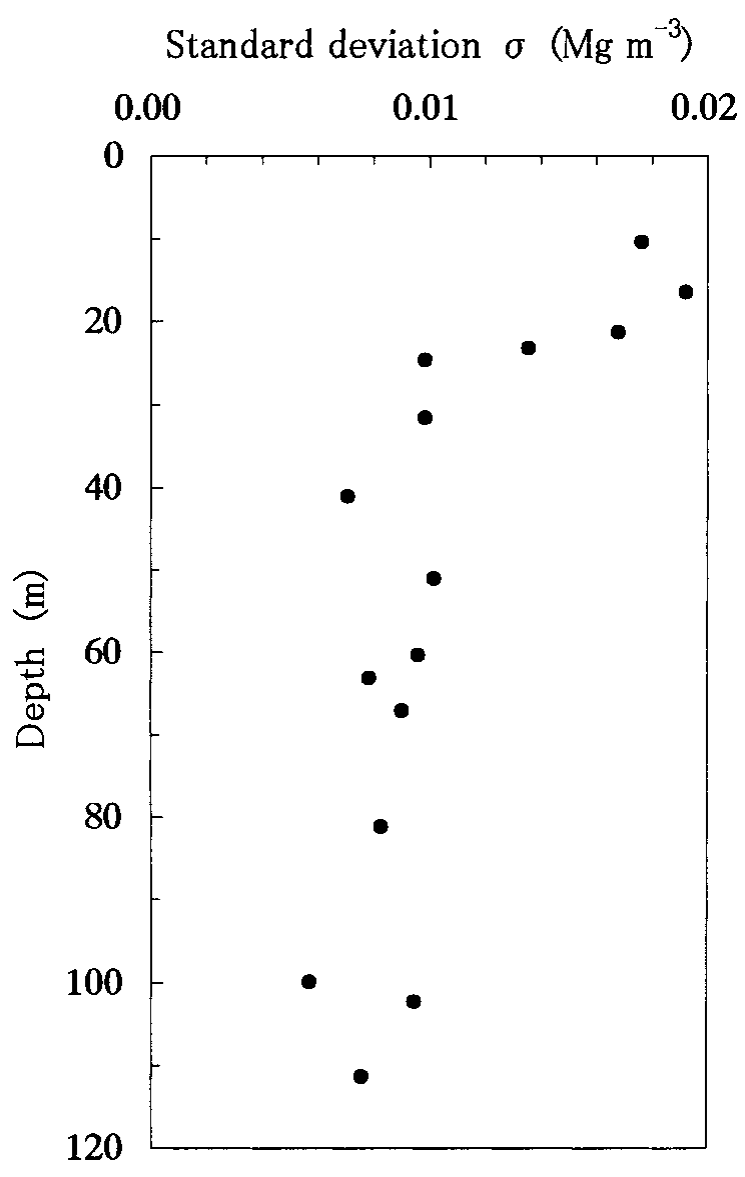

Fig. 3. The standard deviation, $\sigma$, of the density measured by the $X$-ray transmission method. Note the decreasing trend in standard deviation, which ceases at around $25 \mathrm{~m}$ depth where the density is $0.55 \mathrm{Mg} \mathrm{m}^{-3}$. 

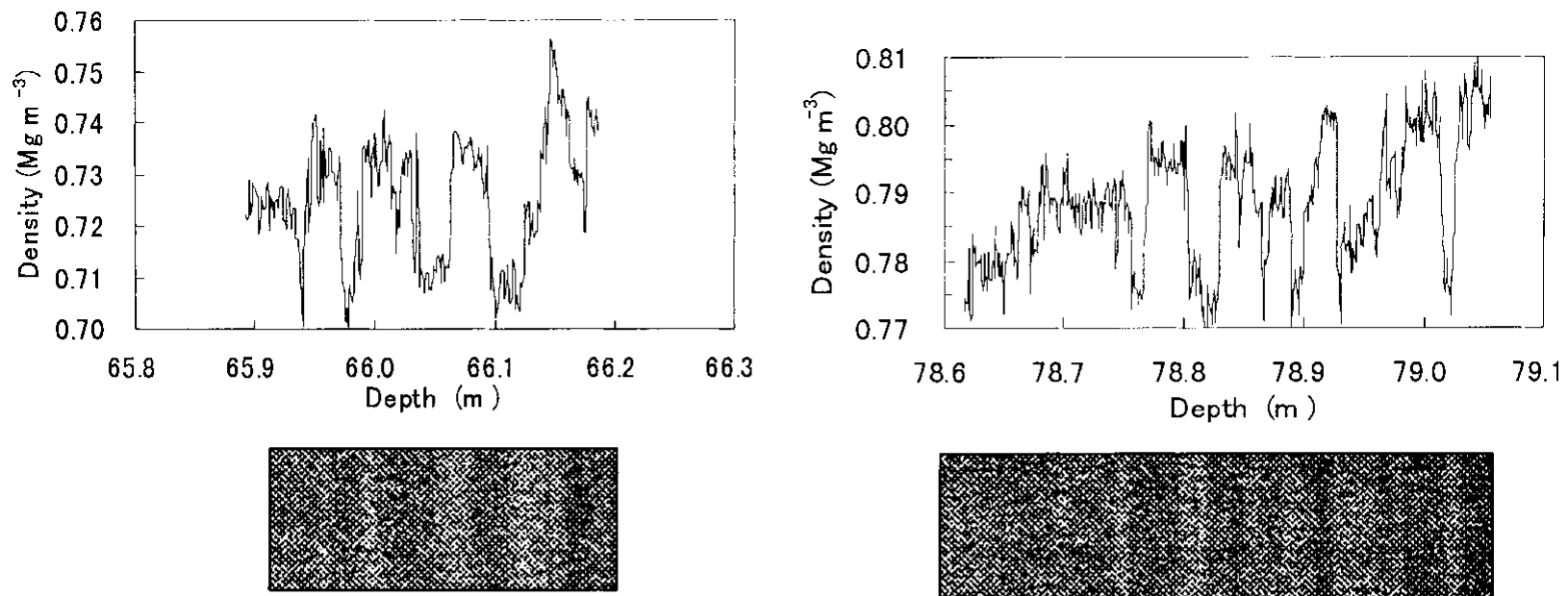

a
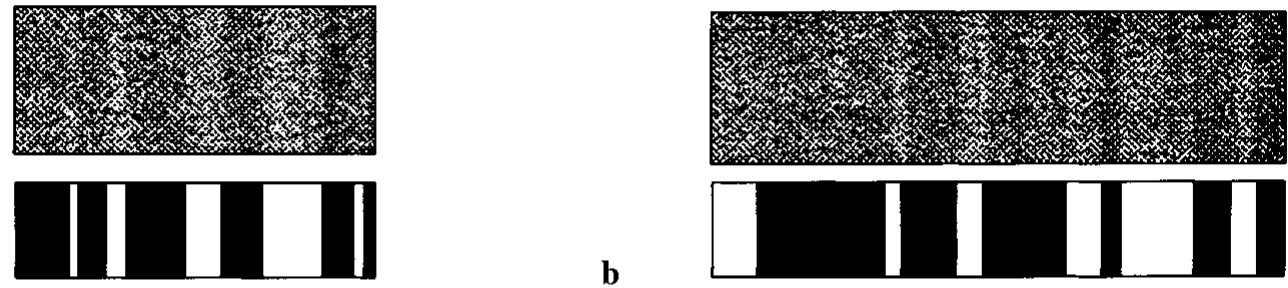

$\mathbf{b}$
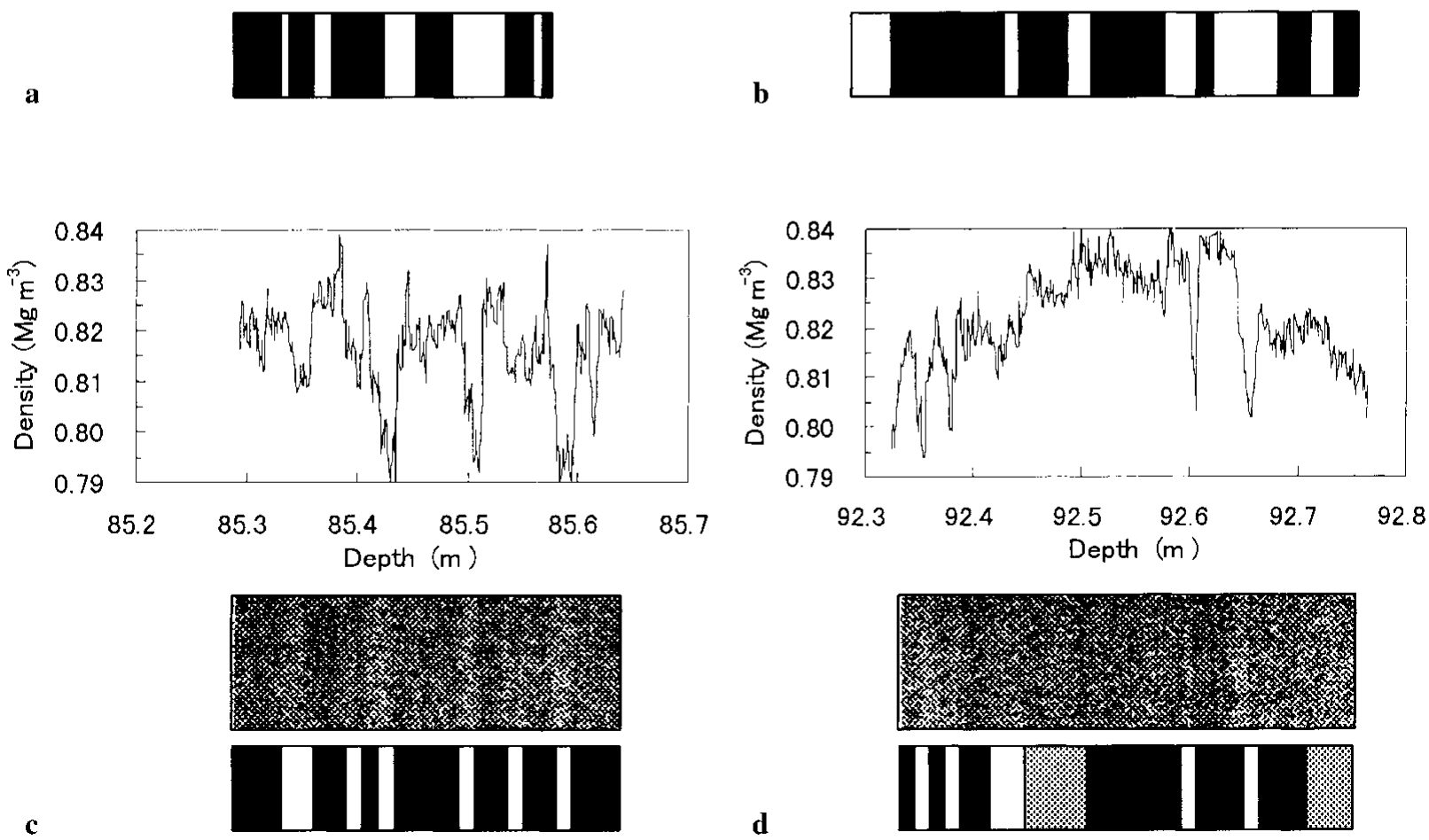

d

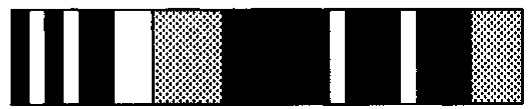

Fig. 4. The density profile of ice-core samples from different depths and the corresponding radiographs. Diagrams below the radiographs show the two-dimensional layer structures seen in the radiographs.

fluctuation of the density was found. Then the standard deviation of the density was calculated for several samples. Figure 3 shows that the standard deviation, $\sigma$, rapidly decreases as depth increases to $25 \mathrm{~m}$, where the average density is about $0.55 \mathrm{Mg} \mathrm{m}^{-3}$. After that, it seems to be almost constant.

In general, three transitions exist in the densification process, around $0.55,0.73$ and $0.83 \mathrm{Mg} \mathrm{m}^{-3}$, and the mechanism of densification changes from the packing of ice particles to their plastic deformation around a density of $0.55 \mathrm{Mg} \mathrm{m}^{-3}$ (Narita and others, 1978). The ice particles are not closely packed at densities of $<0.55 \mathrm{Mg} \mathrm{m}^{-3}$.

In this measurement, the X-ray beamwidth (which is assumed to be the slit width, $0.2 \mathrm{~mm}$ ) is smaller than the average grain-size, even in the shallow ice core (Watanabe and others, 1997a) where the grain-size is reported to be $>0.5 \mathrm{~mm}$. This measurement is therefore considered to be sensitive to the spatial distribution of the grains. Hence, the fluctuation of the spatial distribution of the grains decreases with the increase of the density.

Although the density profile was compared with the
ECM profile measured at the drill site, no definite correlation between them was found except for several short intervals.

\section{Density profile of each sample and its radiograph}

X-ray radiographs of ice-core samples of different depths are shown with the corresponding density profiles in Figure 4. Several dark layers with high density are seen in the radiographs. These layers are perpendicular to the sample axis. In these radiographs, the intensities of X-rays transmitted through the ice core are not converted to densities.

A correlation between density and permeability has been investigated in detail (Langway and others, 1993), and the threshold density for the permeability was estimated at about $0.81 \mathrm{Mg} \mathrm{m}^{-3}$. The permeability of the Dome Fuji shallow ice cores was measured and reported to decrease rapidly from about $80 \mathrm{~m}$ depth (Watanabe and others, 1997a). In Figure $4 \mathrm{a}$, the density is much lower than the threshold value $0.81 \mathrm{Mg} \mathrm{m}^{-3}$, and the sample was permeable. In Figure $4 \mathrm{c}$, the density of some of the dark layers is $>0.81 \mathrm{Mg} \mathrm{m}^{-3}$, 


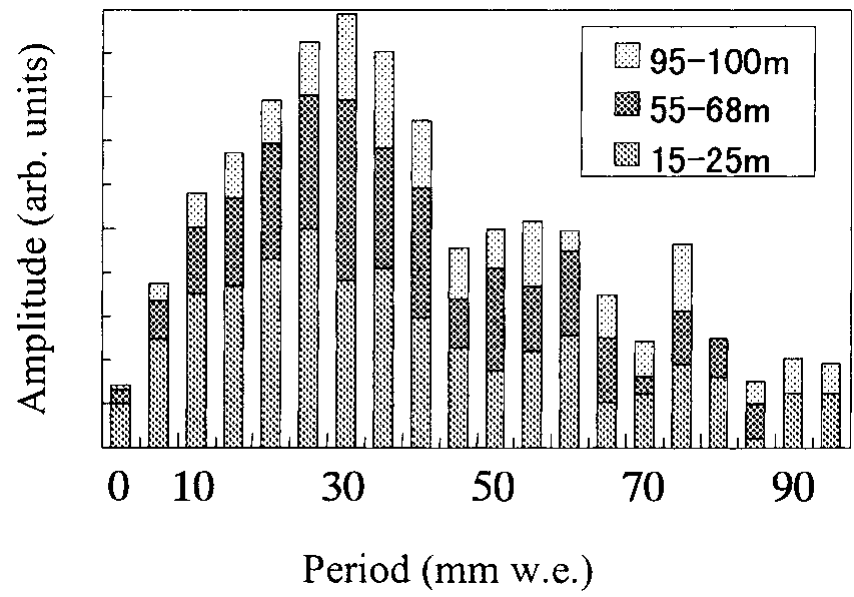

Fig. 5. The integrated spectrum for the Dome Fuji shallow ice cores.

while it does not reach $0.81 \mathrm{Mg} \mathrm{m}^{-3}$ in Figure $4 \mathrm{~b}$. In Figure $4 \mathrm{~d}$, in most parts of the sample, the density is $>0.81 \mathrm{Mg} \mathrm{m}^{-3}$; the permeability of this sample was therefore low. Although the radiographs are used to view the two-dimensional layer structure in this study, two-dimensional numerical data of density can be obtained from the radiographs.

\section{Spectral analyses}

The density profile is generally considered to reflect the seasonal variation, but this was not evident in our results. The power spectrum for each sample was calculated by the DFT. Before this calculation the individual data, $d_{\mathrm{i}}$, were normalized by the average density of the sample, $d_{\mathrm{av}}$. They were then multiplied by the Hanning-type window function $w_{\mathrm{i}}$ which is described as

$$
w_{\mathrm{i}} \equiv \frac{1}{2}\left[1-\cos \left(\frac{2 \pi i}{N-1}\right)\right],
$$

where $N$ is the number of data. Then $\left(d_{\mathrm{i}} / d_{\mathrm{av}}\right) w_{\mathrm{i}}$ is transformed by DFT. Although the calculated peak positions were different for the different samples, the main peaks were located at $30-40 \mathrm{~mm}$ in many samples. For many samples longer than $30 \mathrm{~cm}$, values of the amplitude in the spectra were summed at period intervals of $5 \mathrm{~mm}$. The result is shown in Figure 5. There seems to be a broad peak around $30 \mathrm{~mm}$, which is approximately equal to the annual accumulation at the drill site (Watanabe and others, 1997b). This was almost independent of the depth intervals of the samples.

\section{GONCLUSION}

A detailed density profile for the shallow Dome Fuji ice cores was obtained by a new method, i.e. the X-ray transmission method. Variations of density in the ice cores were found in this detailed profile. A decreasing trend in density standard deviation ceases at around $25 \mathrm{~m}$ depth where the density is $0.55 \mathrm{Mg} \mathrm{m}^{-3}$.

X-ray radiographs showed the existence of thin layers with a high density of $>0.81 \mathrm{Mg} \mathrm{m}^{-3}$, although the average density was $<0.81 \mathrm{Mg} \mathrm{m}^{-3}$. This suggests that the ice may be impermeable. Thus, detailed density profiles and X-ray radiographs of ice cores are effective tools for studying the impermeability of ice cores.

From the density profile obtained, we calculated the power spectrum by DFTand obtained distributions of several peaks at different periods. The center of the distributions of the peaks was found at about $30-35 \mathrm{~mm}$, which is approximately equal to the annual accumulation at the drill site.

\section{REFERENGES}

Gerland, S., H. Oerter, J. Kipfstuhl, F. Wilhelms, H. Miller and W. D. Miners. 1999. Density log of a $181 \mathrm{~m}$ long ice core from Berkner Island, Antarctica. Ann. Glaciol., 29 (see paper in this volume).

Herron, M. M. and C. C. Langway, Jr. 1980. Firn densification: an empirical model. f. Glaciol., 25(93), 373-385.

Langway, G. C., Jr, H. Shoji, A. Mitani and H. B. Clausen. 1993. Transformation process observations of polar firn to ice. Ann. Glaciol., 18, 199-202.

Narita, H., N. Maeno and M. Nakawo. 1978. Structural characteristics of firn and ice cores drilled at Mizuho station, East Antarctica. Natl. Inst. Polar Res. Mem., Special Issue 10, 48-61.

Schwander, J. and B. Stauffer. 1984. Age difference between polar ice and the air trapped in its bubbles. Nature, 311 (5981), 45-47.

Schwander, J., T. Sowers, J. M. Barnola, T. Blunier, A. Fuchs and B. Malaizé. 1997. Age scale of the air in the Summit ice: implication for glacial-interglacial temperature change. f. Geophys. Res., 102, 19,483-19,493.

Tayuki, K., T. Hondoh and H. Narita. 1997. High resolution density profile of ice cores measured by a new X-ray method. (Abstract.) Proc. NIPR Symp. Polar Meteorol. Glaciol. 11, 253.

Watanabe, O. and 12 others. 1997a. Preliminary discussion of physical properties of the Dome Fuji shallow ice core in 1993, Antarctica. Proc. NIPR Symp. Polar Meteorol. Glaciol. 11, 1-8.

Watanabe, O. and 15 others. 1997b. A preliminary study of ice core chronology at Dome Fuji Station, Antarctica. Proc. NIPR Symp. Polar Meteorol. Glaciol. 11, 9-13.

Wilkinson, D. S. 1988. A pressure-sintering model for the densification of polar firn and glacier ice. f. Glaciol., 34(116), 40-45. 